\title{
Development of Mice Embryo (Mus musculus L.) after Closed Pulled Straw Vitrification in CZB Medium
}

\author{
Muhammad Gunawan ${ }^{1 *}$, Ekayanti Mulyawati Kaiin ${ }^{1}$, Raden Cindy Rusherdiannita ${ }^{2}$, \\ Kartiawati Alipin ${ }^{2}$
}

\author{
${ }^{1}$ Research Center for Biotechnology, Indonesian Institute of Sciences (LIPI), Indonesia \\ ${ }^{2}$ Department of Biology, Padjajaran University, Indonesia
}

\begin{abstract}
The objective of our present experiment was to investigate the effects of closed pulled straw (CPS) vitrification on the viability and development of mouse embryo. The experiment was arranged according to completely randomized design (CRD) consisting of 4 treatments, namely not vitrification (NV) is control, CPS 1 (mCZB Hepes $+20 \%$ Bovine Serum Albumin (BSA) $+0.5 \mathrm{M}$ sucrose $+10 \% \mathrm{EG}+10 \%$ DMSO), CPS 2 (mCZB Hepes $+20 \%$ BSA $+0.5 \mathrm{M}$ sucrose $+15 \% \mathrm{EG}+15 \% \mathrm{DMSO})$, and CPS 3 (mCZB Hepes $+20 \%$ BSA $+0.5 \mathrm{M}$ sucrose $+20 \% \mathrm{EG}+20 \%$ DMSO) with 6 replications. The viability of embryos (\%) was determined after $24-$ $72 \mathrm{~h}$ of the culture period, while we also observed the percentage of embryos reaching the blastocyst stage (early blastocyst, expanded, hatching, and hatched). As a result, the treatments did not give a significant difference in the viability of embryos $(\mathrm{P}<0,05)$ but showed significant effects on embryo development $(\mathrm{P}<0,05)$. Furthermore, this present work conclusively found that CPS vitrification in CZB medium with cryoprotectants ethylene glycol (EG) and dimethyl sulfoxide (DMSO) noticeably influenced the development of mice embryo to reach the blastocyst stage, but showed no remarkable difference in the viability of embryo after culture for $24-72 \mathrm{~h}$.
\end{abstract}

Keywords: Mice, Blastocyst, Close Pulled Straw (CPS), Cryoprotectants, CZB Medium

*Corresponding author:

Cibinong Science Center and Botanical Garden, Jl. Raya Bogor Km. 46, Cibinong 16911, Indonesia

Tel. +62-21-8754587, Fax. +62-21-87754588

E-mail. muhammadgunawan@ymail.com

\section{Introduction}

Assisted reproductive technology has been long developed using liquid nitrogen to cryopreserve embryos at $-196^{\circ} \mathrm{C}$, and successfully applied in numerous species such as mouse (Whittingham, 1971), rats (Whittingham, 1975; Kono et al., 1988), sheeps (Willadsen et al., 1976), goats (Bilton \& Moore, 1976) and bovines (Wilmut \& Rowson, 1973). Principally, the technology is designed to preserve embryos for a long period and then used to transfer the embryo for producing new individuals (Kurniawan, 2013).

The embryo cryopreservation is often carried out through two methods, namely the slow cooling method and rapid cooling method (vitrification). The slow cooling method requires very advanced technology; besides, it is expensive to control water release from cells and freezing rate, which make it difficult to operate. Currently, vitrification has received great interests in embryo cryopreservation as it is technically easier to operate in comparison with the slow cooling method. The vitrification method has a very fast freezing rate (ultra rapid cooling) and exceeds the formation point of ice crystals so that it forms a glass like state or vitreous state formation that keeps cells viable during freezing (Pereira \& Marques, 2008; Edgar \& Gook, 2012; Jang et al., 2017). Murakami et al. (2011) asserted that the viability of embryos using vitrification protocol reached $98,1 \%$ until obtaining normal birth.

Furthermore, vitrification could be applied using two mechanisms, i.e. Open Pulled Straw (OPS) and Closed Pulled Straw (CPS). As explained by Vajta et al. (2012), OPS is more susceptible to the contaminants over CPS. In CPS, the embryo was isolated using a special straw covered in both sides, protecting 
embryos against pathogenic contaminants present in liquid nitrogen, in which the presence of such contaminants could noticeably after viability and development of embryo following vitrification. Also, Vajta et al. (2012) demonstrated that CPS could reach successfulness reaching up to $80 \%$, being higher than OPS.

The use of cryoprotectants Ethylene glycol has a low molecular weight and tends to have lower toxicity to mammalian cells than other cryoprotectants, while DMSO is able to penetrate into cells, form a glass like state and increase the rate of permeability when combined with EG. The combination of the two can also increase the viability of oocytes during freezing (Fahy \& Wowk, 2015; Pamungkas, 2010; Hartady et al., 2018).

Our recent experiment performed CPS vitrification using ethylene glycol (EG) and dimethyl sulfoxide (DMSO) as cryoprotectants in Chatot-Ziomek-Bavister (CZB) medium, concerning to its effectivity on viability and development of mice embryos.

\section{Materials and Methods}

\section{Superovulation and Collection of Embryo}

Superovulation in female mice strains DDY (Deutschland Denken and Yoken) at the age of 2,5-3 months involved intraperitoneal injections of $5 \mathrm{IU} / 0,1 \mathrm{ml}$ PMSG (Foligon, Intervet, Netherland) and $5 \mathrm{IU} / 0,1 \mathrm{ml}$ hCG (Chorulon, Intervet, Netherland) with the interval of $48 \mathrm{~h}$ (Kanter et al., 2004). Immediately after administration of hCG, female mice were naturally mated $1: 1$ to the male. In the next morning, the vaginal plug of female was observed to verify the mating. The 3 days-old embryos (morula) were collected through dissecting the tuba fallopi and flushing the uterus, while 4 days-old embryos (blastula) were taken through flushing the uterus using CZB Hepes (Chatot-Ziomek-Bavister) (Chatot et al., 1990) under microscope stereo (Nikon, SMZ-2T, Japan). The observation of morula and blastula was performed using an inverted microscope (Nikon, Japan).

\section{Protocols of Closed Pulled Straw (CPS) Vitrification}

CPS vitrification was conducted using several steps, namely adaptation with modification of CZB medium by reducing $\mathrm{NaHCO}_{3}$ from $25 \mathrm{mM}$ to $5 \mathrm{mM}+$ Hepes (modified CZB Hepes) $+20 \%$ BSA for $5-10$ min. The embryos were then exposed to equilibrium medium (mCZB Hepes $+20 \%$ $\mathrm{BSA}+10 \% \mathrm{EG}+10 \% \mathrm{DMSO}$ ) for $3-5 \mathrm{~min}$. Subsequently, the sample was transferred into vitrification medium. We prepared 4 groups of treament, i.e. control (without embryo vitrification), embryo vitrificationwith various medium compositions: CPS 1 (mCZB Hepes with $20 \% \mathrm{BSA}, 0,5 \mathrm{M}$ sucrose, $10 \% \mathrm{EG}$ and $10 \%$ DMSO), CPS 2 (mCZB Hepes with 20\% $\mathrm{BSA}, 0,5 \mathrm{M}$ sucrose, $15 \% \mathrm{EG}$ and $15 \%$ DMSO) and CPS 3 (mCZB Hepes with 20\% BSA, $0,5 \mathrm{M}$ sucrose, $20 \% \mathrm{EG}$ and $20 \%$ DMSO). In vitrification, 3 - 5 embryos were placed in a special straw with aid of $1 \mathrm{ml}$ syringe connected with cotton plug to hold medium and embryos. The straw was arranged by the size, then sealed. Vitrification was conducted by exposing the straw to liquid nitrogen for $10-20 \mathrm{sec}$, and immediately transferred into liquid nitrogen. The protocol CPS vitrification was based on the method of Kasai (1994) with modification the addition of sucrose $0,5 \mathrm{M}$ as depicted in Figure 1.

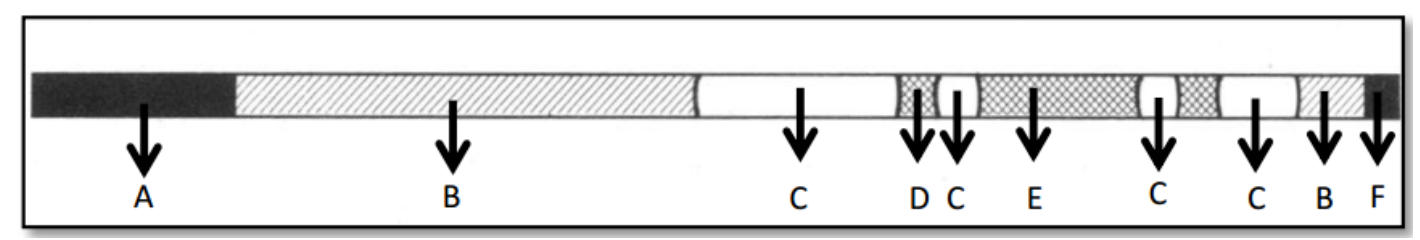

Figure1.The straw was $0,25 \mathrm{ml}$ in size. (A) cotton plug, (B) sucrose $0,5 \mathrm{M},(\mathrm{C})$ air, (D) vitrification medium, (E) embryo in vitrification medium, and (F) sealed straw tip.

\section{Thawing, In vitro culture, and staining}

The frozen straw containing embryo was thawed in water (at room temperature) for 30 sec, drained, and shaken to blend vitrification medium and sucrose, capable of inducing elimination of cryoprotective effect. Immediately after the sealed end of the straw was cut off by sterile scissor, the straw was 
tilted, while the cotton plug was removed, enabling to release medium and embryo. The medium and embryo was then collected in a petridish containing mCZB Hepes $+20 \%$ BSA, and washed 3 times. The 5 - 10 embryos was then transferred into spot $50 \mu \mathrm{l} \mathrm{CZB}$ culture medium in a petri dish. They were then incubated in $5 \% \mathrm{CO}_{2}$ at $37,5^{\circ} \mathrm{C}$. Viability was determined after $24-72 \mathrm{~h}$ of incubation. Afterward, the observation was carried out until hatched blastocyst stage. The viability of embryo was evaluated based on staining with Hoechst $3334210 \mu \mathrm{g} / \mathrm{ml}$ and Propidium Iodide $10 \mu \mathrm{g} / \mathrm{ml}$ (Hoechst-PI) in Dulbecco's phosphate buffered saline (DPBS) medium. Briefly, the embryo was moved from culture medium to DPBS medium containing $0,6 \%$ BSA as a washing medium. The embryo was then placed onto a concave slide glass containing Hoechst-PI, left for $10-15 \mathrm{~min}$, then observed using fluorescent microscope (Imager Z2, Carl Zeiss) at the wavelength of 330-385 nm (Gunawan et al., 2014).

\section{Parameters}

The embryo following CPS vitrification was investigated with respect to the percentage of viability (based on normal morphology, degeneration), after a culture period of $24-72$ $\mathrm{h}$, and percentage of embryo reaching blastocysts (early blastocyst, expansion, hatching, and hatched).

\section{Statistical Analysis}

Data were evaluated using analysis of variance (ANOVA) at significance level of $95 \%$. The significant difference between means was verified using the Duncan's test (Gomez \& Gomez, 2005) in SPSS 19.0 software.

\section{Results}

\section{Viability of Mouse Embryo}

As presented in Table 1, the viability of mouse embryo showed no significant difference between treatments, observed in both life stages of the embryo $(\mathrm{P}<0,05)$. This indicates that both embryonic stages undergo a process known as compaction, allowing them to respond towards vitrification, while the cryoprotectant concentration was at a normal range for the survival of the embryos. The viability was determined by Hoechst-PI staining method, following thawing and culture for $24-72 \mathrm{~h}$. The observation was carried out under fluorescent microscope with a light filter of DAPI and FITC. The embryo with desired viability appeared in blue, due to reaction between Hoechst stain and DNA in blastomere nucleus of viable cells. Conversely, the cellular membrane of the unviable embryo was impermeable; thus, propidium iodide was absorbed into DNA in damaged nucleus, then appeared red colour. The appearance of viable embryo after vitrification was exhibited in Figure 2.

Table 1. Viability of mouse embryo following vitrification and culture treatment

\begin{tabular}{ccccc}
\hline \multirow{2}{*}{ Stages } & Treatments & \begin{tabular}{c} 
Number of \\
embryos \\
\cline { 3 - 5 }
\end{tabular} & & \multicolumn{2}{c}{ Viability of embryo } \\
\cline { 3 - 5 } & & 38 & $\mathbf{2 4} \mathbf{h}$ & $\mathbf{7 2 ~ h}$ \\
MORULA & NV & 38 & $33(86.84)$ & $31(81.58)$ \\
& CPS 1 & 35 & $20(57.14)$ & $31(88.57)$ \\
& CPS 2 & 35 & $16(45.71)$ & $30(85.71)$ \\
& CPS 3 & 35 & $24(68.57)$ & $28(80.00)$ \\
\hline \multirow{3}{*}{ BLASTOCYST } & NV & 64 & $49(76.56)$ & $60(93.75)$ \\
& CPS 1 & 35 & $18(51.43)$ & $26(74.29)$ \\
& CPS 2 & 35 & $25(71.43)$ & $29(82.86)$ \\
& CPS 3 & 35 & $21(60.00)$ & $22(62.86)$ \\
\hline
\end{tabular}



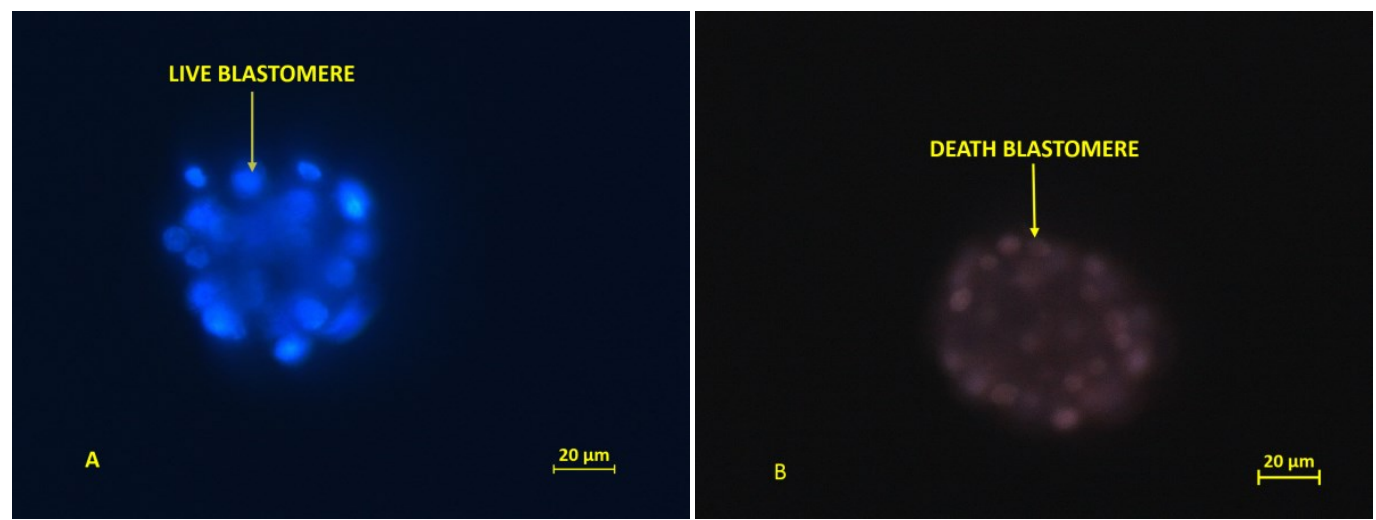

Figure2. Viability of blastocysts following vitrification observed under a fluorescent microscope at magnificent of $400 \times$ with Hoechst-PI staining. (A) live embryo (normal), marked in blue;(B) death embryo (degenerated), marked in red.

\section{Embryonic development following vitrification and culture}

The normal embryo is often recognized from its cellular structure, such as completion of zona pellucida, blastomeres equal in size, homogenous cytoplasmic granularity; conversely, embryo with abnormalities can be characterized from its fracture and degeneration zone. The viable embryo can develop to expanded stage and hatching stage in which the embryo leaves zona pellucida (Sari, 2007). The developmental stage of mouse embryo after vitrification is presented in Table 2 .
The results showed that, in morula-stage embryo, CPS 2 resulted in a higher proportion of embryo that develops to expanded and hatching stage $(P<0,05)$. In terms of the blastocyst-stage embryo, CPS 2 also produced the greater proportion of embryo able to develop to the hatched stage $(\mathrm{P}<0,05)$, in comparison with CPS 1 and CPS 3. In this case, CPS 2 (cryoprotectant concentration of $15 \%$ ) did induce compaction as found in CPS 3 , thus embryo could develop to expanded and hatching stage. Development of mouse embryo after culture for 24-72 $\mathrm{h}$ was depicted in Figure 3.

Table 2. Developmental stage of mouse embryo after vitrification

\begin{tabular}{|c|c|c|c|c|c|c|}
\hline \multirow[b]{2}{*}{ Stage } & \multirow[b]{2}{*}{ Treatments } & \multirow[b]{2}{*}{$\begin{array}{c}\text { Number of } \\
\text { embryo } \\
\text { (n) }\end{array}$} & \multicolumn{4}{|c|}{$\begin{array}{r}\text { Developmental stage of embryo } \\
\end{array}$} \\
\hline & & & $\begin{array}{c}\text { Early stage } \\
\text { blastocyst } \\
\% \\
\end{array}$ & $\begin{array}{c}\text { Expanded } \\
\% \\
\end{array}$ & $\begin{array}{c}\text { Hatching } \\
\%\end{array}$ & $\begin{array}{c}\text { Hatched } \\
\% \\
\end{array}$ \\
\hline \multirow{4}{*}{ MORULA } & NV & 38 & $34(89.47)$ & $31(81.58)^{b}$ & $25(65.79)^{b}$ & $5(13.54)$ \\
\hline & CPS 1 & 34 & $32(91.43)$ & $28(80.00)^{b}$ & $27(77.14)^{b}$ & $0(0)$ \\
\hline & CPS 2 & 35 & $29(82.86)$ & $27(77.14)^{b}$ & $24(68.57)^{b}$ & $2(6.54)$ \\
\hline & CPS 3 & 35 & $26(74.29)$ & $22(62.86)^{\mathrm{a}}$ & $13(37.14)^{\mathrm{a}}$ & $0(0)$ \\
\hline \multirow{4}{*}{ BLASTOCYST } & NV & 64 & $63(98.44)$ & $60(93.75)$ & $55(85.94)^{b}$ & $20(31.25)^{\mathrm{b}}$ \\
\hline & CPS 1 & 35 & $33(94.29)$ & $33(94.29)$ & $29(82.86)^{\mathrm{ab}}$ & $3(8.57)^{\mathrm{a}}$ \\
\hline & CPS 2 & 35 & $33(94.29)$ & $31(88.57)$ & $26(74.29)^{\mathrm{ab}}$ & $6(17.14)^{\mathrm{ab}}$ \\
\hline & CPS 3 & 35 & $31(88.57)$ & $28(80.00)$ & $17(48.57)^{\mathrm{a}}$ & $1(2.86)^{\mathrm{a}}$ \\
\hline
\end{tabular}

Note: Different superscripts following means in the similar column indicate significant difference among treatments based on Duncan statistical test 

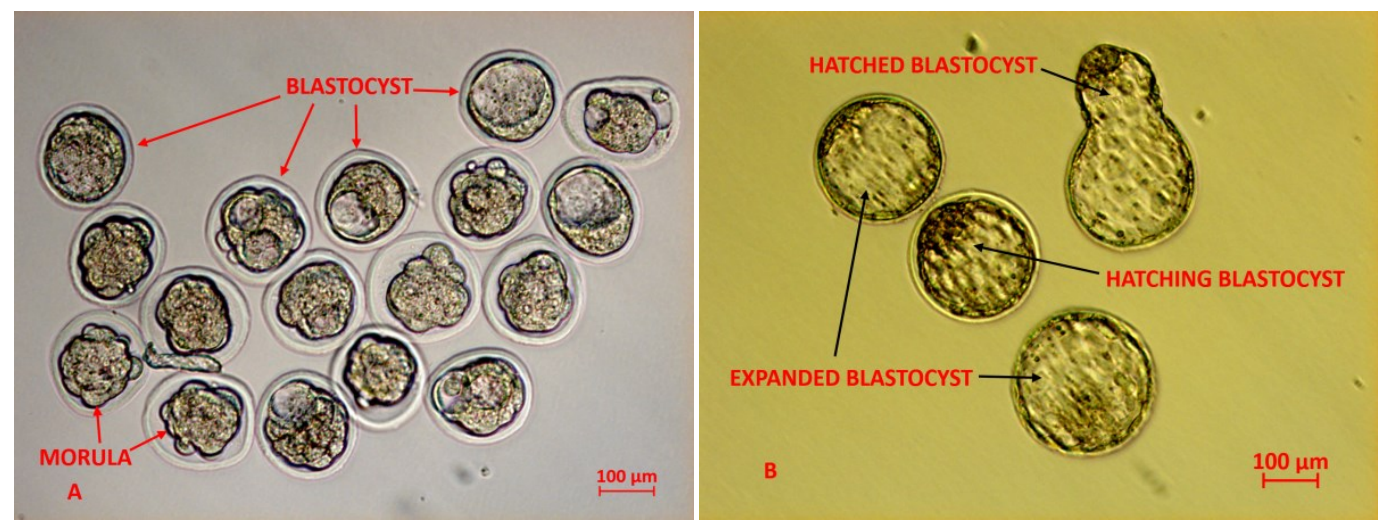

Figure 3. Embryo observed at magnification of $200 \times$, (A) morula- and blastocyst-stage embryo prior to vitrification; (B) development of embryo after vitrification and culture for 24-72h.

\section{Discussion}

\section{Viability of Mouse Embryo}

The viability of mouse embryo showed no significant difference between treatments, observed in both life stages of the embryo $(\mathrm{P}<0,05)$. This indicates that both embryonic stages undergo a process known as compaction, allowing them to respond towards vitrification, while the cryoprotectant concentration was at a normal range for the survival of the embryos. Alarcon \& Marikawa (2004) found that, during compaction, the blastomere were less degenerated as they already differentiated to form two types of cell population called inner cell mass and trophoblast, capable of assisting the embryonic viability.

In terms of CPS 1 and CPS 2, the viability of embryo at the morula stage reached $88,57 \%$ and $85,71 \%$, being higher than CPS 2 that at blastocysts stage reaching up to $82,86 \%$. This presumably indicates less cryoprotectants penetrating to cells, considering that morula consists of blastomere. On the other hand, blastocysts are comprised of blastomeres and blastocoel cavity. Consequently, more cryoprotectant penetrates to the cells, enabling to raise the concentration of intracellular and formation of ice crystal. Vanderzwalmen et al. (2002) demonstrated that existence of blastocoel cavity in blastocysts positively related to main cause of destruction following vitrification, as the cryoprotectant was uneasy to penetrate into the cavity, which in turn, lowering the viability.

Destructed blastocoel cavity can be one of the disorders promoted by vitrification. As described by Shostak (1991), besides macromolecules, the blastocysts also contain a large amount of fluid in blastocoel as a result of secretion by blastomere, which is less permeability to cryoprotectants. In short, the blastocoelic fluid in the cavity could alleviate the penetration of cryoprotectants, leading to an increase in ice crystal formation.

Degeneration of embryo after vitrification accounts for the decrease in the low survival rate of embryo, marked with the occurrence of physical and chemical changes due to strong physiological stress. The damages in cellular morphology cannot be excluded, such as fracture zone, lysis and degeneration on the membrane, as well as damages in intracellular organelles unable to observe under the microscope (Miyake et al,.1993 as cited by Sari, 2007).

Furthermore, our present study showed that the viability was higher in the blastocyst-stage embryo $(71,43 \%)$ than in morula-stage embryo $(68,57 \%)$ following vitrification and culture for $24 \mathrm{~h}$. This is possible in the blastocyst stage after being cultured for 24 hours to be able to return to morphological conditions such as before vitrification. In agreement with the previous study of Joung-Jun Park et al. (2012), with the aid of staining, the blastocyst showed a higher rate of normal morphology than morula. In the blastocyst-stage embryo, the presence of lipid molecules in blastomeres plays a crucial role in supporting the early development of the embryo, thus resulting in a higher survival rate.

The exposure period could be a significant factor affecting the effectivity of vitrification. After exposed to hypotonic solution, the volume of the embryo may expand; in contrast, exposure to hipertonic solution triggers 
shrinkage. Zhang et al. (2009) found that a high concentration of cryoprotectant resulted in a higher extracellular osmotic pressure (at concentration of $20 \%$ ) than intracellular osmotic pressure.

The success of maintaining viability of post-vitrified oocytes is influenced by the use of cryoprotectant types and the combination of cryoprotectant concentrations used during the vitrification process (Fahy \& Wowk, 2015). Combination of both cryoprotectants (EG and DMSO) offers advantages. In this case, EG and DMSO enables to facilitate the glassforming process and possesses better permeability compared to other cryoprotectants, which brings desired effects on freezing, viability, and development of the embryo.

Furthermore, we noticed that failure in the further developmental stage of the embryo was not only caused by a difference in concentration of vitrification medium, but also embryo abnormalities which make it degenerated. Based on Hawes \& Latham (2000), such abnormality particularly existing in embryo fragmentation could be linked to exogenous and endogenous factors. The exogenous factor closely related to treatments of vitrified embryo and culture conditions, while endogenous factor included quality of embryo as well as technical errors in collecting embryo.

The level of viability after vitrification in morula embryos and blastocysts in 72 hours cultures is better than in 42 hours cultures. Extension of culture time after vitrification gives the optimal time the embryo returns to its original state. According to the research of Succu et al. (2017) that sheep oocytes after vitrification-thawing process requires incubation time before returning to normal.

\section{Embryonic development following vitrification and culture}

The results showed that, in morula-stage embryo, CPS 2 resulted in a higher proportion of embryo that develops to expanded and hatching stage $(P<0,05)$. In terms of the blastocyst-stage embryo, CPS 2also produced the greater proportion of embryo able to develop to the hatched stage $(\mathrm{P}<0,05)$, in comparison with CPS 1 and CPS 3. In this case, CPS 2 (cryoprotectant concentration of $15 \%)$ did induce decompaction as found in CPS 3, thus embryo could develop to expandedand hatching stage. As explained by Kasai (1994), decompaction of embryo involves changes in internal conditions which causes blastomeres to adhere to one another leading to maximum intercellular contacts, induced by the presence of the harmful substance. In a high concentration, EG and DMSO was reported capable of triggering decompaction, which discontinued development of the embryo, even though the blastomeres are still viable (Hafes , 2000). The research of Chaves et al, (2014) reported that EG and DMSO act as a deterrent to ice crystals during the vitrification process because EG and DMSO have the ability to penetrate into cell membranes and maintain cells during the freezing process.

The Treatment CPS 1 and CPS 2 produced greater number of the embryo developing to expansion in the morula-stage embryo $(80,00 \% ; 17,14 \%)$ and in the blastocyst-stage embryo (94,29\%; 88,57\%). Zhang et al. (2009) found that, in the blastocyst stage, blastomeres undergo expansion which increases the volume of the embryo, and such increment of the volume tends to be more intensive in embryo with no blastocoel cavity. In the blastocystsstage embryo, we noticed that the cellular expansion was hampered by the existence of blastocoelic fluid. Interestingly, our experiment could show a high percentage of expansion stage up to $70-85 \%$, being greater than previous studies. The discrepancy of the results may result from difference in concentration of vitrification, environmental factors, quality of the mice embryos, as well as technical skills of researchers (Sari, 2007).

This present work used CZB as culture medium, which differed from the medium used in other studies, such as KSOM, CR1, TCM199. The use of CZB was based on its capability in avoiding cellular blocks often existing in mouse cells since it contains EDTA and glutamine. CZB also contains anorganic salts $(\mathrm{NaCl}$ and $\mathrm{KCl})$ that act in controlling osmolarity, as well as possesses both essential and non-essential amino acids for metabolic activities of the pra-implanted embryo. Hence, such substances are meaningful in supporting the embryonic development; in this case, sodium pyruvate, lactic acid, and glutamine serve as a source of energy while $\mathrm{NaHCO}_{3}$ acts to maintain $\mathrm{pH}$ in medium without altering the concentration of $\mathrm{CO}_{2}$ (Kasai, 1994). 
Addition of HEPES into CZB medium serves as a buffer, stabilizing $\mathrm{pH}$ of 7,2-7,6 that is known as an optimum level for praimplanted embryo and able to protect it against destruction. CZB medium also contains BSA in order to assist in vitro embryonic development.

The effectivity of vitrification is also influenced by the use of extracellular cryoprotectant able to preserve membrane of the embryo and alleviate toxicity (Szell\&Shelton, 1986). This enables to induce a rapid embryonic shrinkage after releasing cryoprotectants (EG and DMSO) within cells during thawing. However, the cells could turn back their size following $1 \mathrm{~h}$ of incubation, allowing the embryo to undergo recovery after vitrification.

Hafes (2000) reported that freezing induced by vitrification could affect the activity of pronase, a proteolytic enzyme capable of altering bonds between cells and cytoskeletal blastomeres during decompaction, reducing them to adhere to one another. In our experiment, CPS 2 exhibited the highest percentage of the hatched embryo, since the concentration of cryoprotectant at $15 \%$ is still in the acceptable range for the embryo to perform compaction of blastomeres due to pronase activity as not existed in CPS 3. Thus, despite the low rate $(5,71 \%)$, hatched stage in morula was still found in this treatment.

Development of morula-stage embryo was lower than that of a blastocyst-stage embryo. Morula takes a longer time to grow and develop to reach early blastocysts following vitrification. Differently, blastocyst could accomplish compaction of blastomeres with a larger number of cells, thus it can develop faster than morula. This is in agreement with that reported with Mohammad et al. (1999).

With regard to CPS 1, the growth of embryo was low due to deficient concentration of cryoprotectant, thereby unable to preserve embryo perfectly. During freezing, water penetrating to an embryo would be released and then substituted by cryoprotectant able to secure the viability (Sari, 2007). With a dose of $10 \%$, CPS 1 did not give optimum effects on preservation of the embryo, since it still remained empty cavities. As a result, the formation of crystal ice cannot be avoided, then leading to destructive effects on the developmental stage of the embryo.
Similarly, in the blastocyst-stage embryo, CPS 2 could significantly treat embryo to reach the hatched level, better than CPS 1 and CPS 3. This may indicate that CPS 2 was still tolerable towards osmotic stress. As discussed by Tachikawa et al. (1993), blastocyst was comprised of small size-blastomeres which make them more susceptible to osmotic stress. For this reason, CPS 3 resulted in a harmful effect that is intolerable by the embryo.

The changes in the volume of embryo induced by CPS 2 are still acceptable, associated with hyperosmotic effect due to the formation of extracellular ice crystals. At a dose of $15 \%$, the volume was not greater than the addition of $20 \%$ cryoprotectant; thus, optimum recovery could be achieved. At a dose of $20 \%$, the stronger toxic effect may occur, enabling to reduce the viability of the cells and embryo. The use of a combination of cryoprotectant EG $15 \%(\mathrm{v} / \mathrm{v})$ and $15 \%(\mathrm{v} / \mathrm{v})$ DMSO have lower levels of toxicity to cells compared to the use of one type of cryoprotectant or cryoprotectant combination with higher concentrations in the vitrification method (Pamungkas, 2010; Best, 2015).

When exposed to EG and DMSO, the intracellular fluid was released rapidly, then substituted by cryoprotectant until equilibrium level. Addition of sucrose $0,5 \mathrm{M}$ in medium serves to pull cryoprotectant out the cells, thus changing the volume into the initial state. The use of $0.5 \mathrm{M}$ sucrose proves that the $0.5 \mathrm{M}$ sucrose concentration used in the oocyte vitrification method has been able to reduce the osmotic pressure in the process of oocyte vitrification (Chen et al., 2000).

This study indicated that CPS vitrification in CZB-Hepes medium with cryoprotectants $15 \%$ ethylene glycol and $15 \%$ dimethyl sulfoxide noticeably influenced the development of mice embryo to reach the blastocyst stage.

\section{Acknowledgements}

Thanks to Mr. Rahmat Aminudin and Aditia Dwi Cahyo for technical assistance in this research.

\section{References}

Alarcon, V., \& Marikawa, Y. (2004). Molecular Study Of Mouse Pre-Implantation Development 
Using The In-Vitro Culture Of Aggregated Inner Cell Mass. Journal Molecular Reproduction Development, 67, 83-90.

Best, B. (2015). Cryoprotectant Toxicity: Facts, Issues, and Questions. Rejuvenation Research, 18(5), 422-436.

Bilton, R. J., \& Moore, N. W. (1976). In vitro cultur, storage and transfer of goat embryos. Australian Journal of Biological Sciences, 29, 125-129.

Chatot, C., Ziomek, C., Bavister, B., Lewis J., \& Torres I. (1990). An improved culture medium supports development of random-bred 1-cell mouse embryos in vitro. Journal of Reproduction and Fertility, 86, 679-688.

Chaves, D. G., Gonçalves de Souza-Fabjan J. M., Mermillod, P., \& V.J. de Figueirêdo Freitas. (2014). Factors that affect oocyte vitrification in small ruminants. Revista brasilerira de medicina veterinaria, 21(2), 69-75.

Chen, S. U., Lien, Y. R., Cao, K. H., Lu, H. F., Ho, H. N., \& Yang, Y. S. (2000). Cryopreservation of mature human oocytes by vitrification with ethylene glycol in straws. Fertility and Sterility, 74(4), 804-808.

Edgar, D. H., \& Gook, D. A. (2012). A critical appraisal of cryopreservation (slow cooling versus vitrification) of human oocytes and embryos. Journal Human Reproduction Update, 18(5), 536-554.

Fahy, G. M., \& Wowk, B. (2015). Cryopreservation and freeze-drying protocols. $3^{\text {rd }}$ ed. Humana Press, Germany, 509 hlm.

Gomez, K., \& Gomez. A., (2005). Prosedur Statistik Untuk Penelitian Pertanian, edisi kedua, UI Press, Jakarta

Gunawan, M., Fahrudin, M., \& Boediono, A. (2014). Perkembangan embrio sapi setelah fertilisasi menggunakan metode Intracytoplasmic Sperm Injection (ICSI) dan aktivasi dengan strontium. Jurnal Kedokteran Hewan, 8(2), 154-157.

Hafes, E. S. E. (2000). Reproduction in Farm Animals $7^{\text {th }}$ Edition. Philadelphia. USA.

Hartady, T., Widyastuti, R., \& Syamsunarno, R. A. A. (2018). Viabilitas oosit domba pasca vitrifikasi menggunakan kombinasi ethilen glikol dan dimetil sulfoksida dengan dua level konsentrasi yang berbeda. Jurnal Ilmu Ternak, 18(1), 17-21.

Hawes, S., \& Latham, K. (2000). Effect of Paternal Genotype on Embryo Fragmentation at The 2 Cell Stage of Mouse Embryogenesis. Temple
University School of Medicine. Philadelphia. [Abstract].

Jang, T. H., Park, S. C., Yang, J. H., Kim, J. Y., Seok, J. H., Park, U. S., Choi, C. W., Lee, S. R., \& Han, J. (2017). Cryopreservation and its clinical applications. Journal Integrative Medicine Research, 6, 12-18.

Joung-Jun Park, Y., Han, C., Hye, W., Choon, P., \& Boh, Y. (2012). Cryopreservation of Embryo by Concentration Of Ethylene Glycol and Day 6,7,8,9, Embryo in Korean Native Cattle (Hanwo). Journal Embryo Trans., 27(4), 253258.

Kanter, M., Yildiz, C., Meral, I., Koc, A., \& Tasal. I. (2004). Effect of a GnRH agonist on oocyte number and maturation in mice superovulated with eCG and hCG. Theriogenology, 61, 393398.

Kasai, M. (1994). Cryopreservation of Mamalian Embryos by Vitrification. In $\mathrm{T}$, Mori., $\mathrm{T}$, Anono., T, Tominagana., Serono Symposia Publication Rome, 481-219.

Kono, T., Suzuki, O., \& Tsunoda, Y. (1988). Cryopreservation of rat blastocysts by vitrification. Cryobiology 25, 170-173. doi:10.1016/0011-2240(88)90011-9.

Kurniawan, G. H. (2013). Kriopreservasi dalam Teknologi Reproduksi Buatan. Denpasar: Fakultas Kedokteran Udayana.

Miyake, T., Kasai, S., Hu, T., \& Machida, T. (1993). Vitrification of mouse oocytes and embryos at various stage of development in an ethylene glycol-based solution by a simple method. Theriogenology, 40, 121-134.

Mohammad, K., Eriani, K., Djuwita I., \& Boediono, A., (1999). Perkembangan in vitro dan in vivo Embrio Mencit Tanpa Zona Pelusida. Media Veteriner, 6(2), 1-4.

Murakami, M., Egashira, A., Murakami, K,. Araki, Y., Kuramoto, T. (2011). Perinatal outcome of twice-frozen-thawed embryo transfers: aclinical follow-up study. Fertil Steril, in press

Pamungkas, F. A. (2010). Pemanfaatan metode vitrifikasi untuk kriopreservasi mammalia. Jurnal WARTAZOA, 20(3), 112-118.

Pereira, R. M., \& Marques, C. C. (2008). Animal oocyte and embryo cryopreservation. Cell Tissue Banking, 9, 266-267.

Rall, W., \& Fahy, G. (1985). Ice-free cryopreservation of mouse embryos at $-196^{\circ} \mathrm{C}$ by vitrification. Nature, 313, 573-575.

Sari, A., (2007). Fisiologi Kedokteran. Jakarta: Bamboedoea communication 
Shostak, S. (1991). Embryologi an Introduction to Development Biological. Harper Collins Publisher. Pitssburgh, 778pp.

Succu, S. Gadau, S. D., Serra, E., Zinellu, A., Carru, C., Porcu, C., Naitana, S., Berlinguer, F., \& Leoni, G. G. (2017). A recovery time after warming restores mitochondrial function and improves developmental 3 competence of vitrified ovine oocytes. Theriogenology, 1-6.

Szell, A., \& Shelton, J. (1986). Sucrose dilution of glycerol from mouse embryos frozen rapidly in liquid nitrogen vapour. $J$ ReprodFertil 76, 401408.

Tachikawa, S., Otoi, T., Kondo, S., Machida, T., Kasai, M. (1993). Succesful vitrification of Bovine Blastocysts derived by in vitro maturation and fertilization. Mol. Reprod Dev., 34, 266-271.

Vajta, G., Rienzi, L., Cobo, A., Paffoni, A., Scarduelli, C., Capalbo, A., Remohí, J., Ragni, G., \& Ubaldi, F. M. (2012). Consistent and predictable delivery rates after oocyte vitrification: an observational longitudinal cohort multicentric study. Hum Reprod., 27(6), 1606-1612.

Vanderzwalmen, P., Bertin, G., Debauche, C., Standaert, V., Roosendaal, E.V., Vandervorst,
M., Bollen, N., Zech, H., Mukaida, T., Takahashi, K., \& Schoysman, R. (2002). Birth After Vitrification at Morula and Blastocyst Stages: Effect Of Artificial Reduction Of The Blastocoelic Cavity Before Vitrification. Human Reproduction, 17(3), 744-751.

Whittingham, D. G. (1971). Survival of mouse embryos after freezing and thawing. Nature, 233, 125-126. doi:10.1038/233125a0.

Whittingham, D. G. (1975). Survival of rat embryos after freezing and thawing .Journal of Reproduction and Fertility, 43, 575-578. doi:10.1530/jtf.0.0430575.

Willadsen, S. M., Polge, C., Rowson, L. E. A., \& Moor, R. M. (1976). Deep freezing of sheep embryos. Journal of Reproduction and Fertility, 46, 151-154. doi:10.1530jrf.0.0460151.

Wilmut, I., \& Rowson, L. E. (1973). Experiments on low-temperature preservation of cow embryos. Veterinary Record, 92, 686-690.

Zhang, S., Ling, X., Cao, J., Peng, J., Heng, X., \& Tong, G. (2009). Effect of cryotopvitrification on preimplantation developmental competence of murine morula and blastocyst stage embryos, Reprod.Biomed.Online1, 9(5), 708-713. 